\title{
Investigating the Predictors of the International Baccalaureate Diploma Programme Outcome Scores
}

\author{
Öykü DULUN ${ }^{*}$
}

\begin{abstract}
The main purpose of this investigation was to explore the predictors of the International Baccalaureate Diploma Programme (IBDP) outcome scores. A purposive sample of 123 high school students was drawn from a selective private school in a city in Eastern Turkey. Multiple regression analyses were conducted for one dependent variable: Diploma Programme outcome scores by using the independent variables: students' International General Certificate of Secondary Education (IGCSE) scores, English scores and IBDP mock exam score variance. The model found to explain $76 \%$ of the DP outcome scores. It was found also found that the English levels of the students were not considered by teachers as important as they should be. If students could increase their English achievement level in IGCSE by 1 point, their IBDP results would increase .21 points. This means that the prospective IBDP students and their teachers must consider students' English achievement level as well as their achievement level in IGCSE exam for each course when they are to register for IBDP. The model built as a result of this study can be used by IBDP teachers, coordinators, and students to predict the achievement level of students in the end of IBDP.
\end{abstract}

Keywords: International baccalaureate diploma programme, success predictors, international Education.

* Orcid ID: https://orcid.org/0000-0002-2808-5929, Assist. Prof., Yeditepe University, Faculty of Education, Department of Educational Sciences, Curriculum \& Instruction, oyku.dulun@yeditepe.edu.tr 


\section{INTRODUCTION}

At present, over 5,130 national and international schools all around the world follow one of the curricula originally developed by International Baccalaureate Organisation (IBO) for international schools (IBO, 2019). International Baccalaureate Organisation was established as a non-profit organisation in 1968 to offer international programmes for primary and middle years and also secondary education. The International Baccalaureate Diploma Programme (IBDP) offered by IBO in secondary education level to prepare students for the university is a highly rigorous and challenging programme (IBO, 2018). IBDP should be considered more than an international high school programme to prepare the students for the university due to its aim to prepare the students for a sustainable future (Kamalaldin, Michel, \& Sweet, 2016). In order to support students' need of preparation for such a rigorous and challenging programme, schools are looking for ways to implement such a curriculum in grade 9 and 10 to help decreasing the stress levels and increasing the academic achievement levels of students as perceived by the students' themselves.

Although the programmes offered by IBO can easily be implemented in international schools to foster international mindedness due to the mission and the philosophy of the International Baccalaureate (IB), these programmes can also be adapted to any kind of national curriculum. International education is defined by Thompson (1998) as an education to promote international mindedness which perfectly matches with the mission and the philosophy of IB programmes since it aims to develop global citizens who have an intercultural understanding and respect for various differences (IBO, 2017). Considering the mission statement of IB as an international body offering prestigious international education framework to schools promising to help students to act responsibly in their local and global communities, IB programmes are currently offered in over 150 countries. As of 2019, there are 50 schools in Turkey that implement the IBDP. All but four of these schools are private schools; heavily populated by Turkish nationals. Official statistics indicate that 40 out of these 50 IB schools follow an alternative pathway to IBO's Middle Years Programme (MYP)-IBDP sequence; combining either national or some other curriculum before IBDP (IBO, 2019).

\section{Preparation for the IBDP}

In Turkey, there are three different approaches that schools use to prepare students for the IBDP. Firstly, all schools in Turkey are required to follow the national curriculum developed by the Ministry of National Education (MoNE). National schools that offer the IBDP in addition to the national programme will provide students with enrichment activities in grades 9 and 10 to prepare them for the international programmes. Secondly, some schools have opted to enhance their lower high school programmes (i.e., grades 9 and 10) by implementing the International General Certificate of Secondary Education (IGCSE) offered by the Cambridge Assessment International Examinations (CAIE); it is known as the world's largest international qualification for 14-16 years old students in 6,100 schools in more than 145 countries (CAIE, 2018a). Currently, there are about 17 
schools delivering the IGCSE curriculum in Turkey. There are five schools in Turkey offering both the IGCSE curriculum and the IBDP. There are 11 schools implementing another IB programme called the IB Middle Years Programme (IBMYP) which is designed for grades 6 through 10 . These three preparatory programmes implemented by the MoNE, IBO and the CAIE are at the focus of the current investigation and are described below.

MoNEP consists of a 12-year compulsory education including primary school (grade 1 to 4), middle school (grade 5 to 8), and high school (grade 9 to 12). Students who complete primary education continue to middle school without any examination. In middle school students are offered a more flexible education according to their skills and needs. MoNEP offer elective courses in six areas: Language and Expression, Foreign Languages (English), Science and Mathematics, Arts and Sports, Social Sciences, Religion, Morality and Values. Students take 36-37 class hours per week, 8 of which are elective courses.

Following middle school, students take a standardized exam to continue secondary education in high schools that offer academically strong and good quality education. Students have 35 class hours per week in general high schools; whereas in the schools which are accredited by IBO and IGCSE they have 34-45 class hours in grade 9 and 40-45 hours from grade 10 onwards. MoNEP allows these schools to teach all the lessons in English except for Turkish language and literature, and history. These schools are also allowed to implement their own elective biology, physics and chemistry lessons in high school prep year, grades 9 and 10. In prep year the curriculum offers: Turkish, first and secondary language, physical education, elective language and expression, mathematics and science courses, elective arts, elective information and communication technology courses. The prep year is required in these schools to ensure that the students have the necessary abilities in speaking, writing, and reading in the English language to study in an international programme. In grades 9 and 10 the curriculum offers the same courses as the other general high schools.

Through a student's schooling, including their lower secondary school years, the MoNE curriculum aims to develop students' physical abilities, cognitive skills, moral values, social skills, and cultural understandings. The MoNE's other purpose is to build healthy, balanced and dynamic relationships between education and employment by fostering respect for human rights and democracy in preparation for the students' future. With this focus, students are also encouraged to improve their self-confidence, self-control and sense of responsibility as life-long learners while they are adopting a positive work habit and solidarity. Equally important, MoNE develops students' creative and critical thinking skills along with teaching them a foreign language so that they can follow global developments. To perform their improved skills students are also expected to enhance their educational experience by completing a project which is created using their own knowledge and skills (MEB, 2014).

One of these alternative ways to prepare students for the academic rigour of IBDP is International General Certificate of Secondary Education (IGCSE) certificate programme which is offered for grade 9 and 10 students. 


\section{International General Certificate of Secondary Education (IGCSE)}

This international programme is considered to help high school students aged between 14-16 years to improve their performances by developing their skills in creative thinking, inquiry and problem solving in their preparation for other Cambridge programmes and for the IBDP (CAIE, 2018b). Thus, it is a springboard to advanced study with its flexible syllabi which provides opportunities for local and national programmes to adapt it for their own particular situation.

\section{Problem Statement}

In Turkey, investigations into the outcomes of the Diploma Programme and challenges faced during the preparation stages from students' perspectives followed in order to prepare the junior high school students for IBDP and the internationally recognized IGCSE exam are limited (Çorlu (2014); Sagun \& Çorlu (2014); Dulun, Lane, \& Ateşkan (2018). The IBDP students have been known to experience stress related to rigorous academic requirements of the programme (Suldo, 2008). To decrease the stress level of IBDP students, there needs to be more focus on developing the required level of content knowledge, communication, social, research, self-management, and thinking skills which are also the set of skills that are required by hiring executives (Trilling \& Fadel, 2009). As IB philosophy claims to educate the students fort he life beyond the school, the schools which are preparing the students fort he IBDP must be aware of the skill set required by this highly rigorous programme. Kaplan (1998) mentions that IB learner profile attributes are helping the students to become self-regulated and self-regulated learners can revise their learning processes to self- monitor their own learning for necessary interventions (Zimmerman \& Schunk, 1989). As they achieve self-regulation, their stress levels might decrease to a level that would not have an impact on students' academic achievement. In an effort to address this personal need and to contribute to the limited knowledge base, it was investigated whether some variables have comparable strength in predicting the diploma programme outcome scores (dp). Some other factors having a role in students' development of these cognitive and affective skills are also known to be the learning experiences they were exposed in junior high school years (Dulun, 2018). One of these programmes which is implemented in Turkish high schools is the IGCSE with its similar exam structure to IBDP exams. The schools which are following this international certificate programme in grade $9 \& 10$ are aiming to prepare the students for IBDP. Therefore, as an IBDP teacher and an IB educator network (IBEN) member in Turkey, the author of this article got the insight to conduct this research in Turkey. Particular problems of her own experiences with the programme encouraged her to think of a way to provide the parents and the candidates with some statistical data to support the candidates' choices of academic subjects during their IBDP studies. The IBDP students when they complete their grade 10 studies are required to select 6 subjects to study during IBDP in grade 11 and 12. The decision to select these 6 subjects to study in IBDP for two years at high school is made by the students themselves. However the students and the parents usually find this decision making process difficult at first place. One of the 
reasons is that the majority of the students cannot decide at which university they would like to study and thus which courses they should study during the IBDP. Second reason is that they usually have to consider their prediction of their own success in IBDP based on their previous grade 9 and 10 learning experiences which might cause a false perception of success due to the differences in level of difficulties in the curriculum implemented during the junior high school years and IBDP. Besides many other challenges that the IBDP students and their parents face at the beginning of the DP, this investigation aims to provide a reliable and statistical data to support the students' decision making processes for a successful IBDP outcome score. The school administration, IBDP coordinator, counselors and the teachers can also have a great benefit to predict their students' academic achievement level in IBDP with the help of the predictors explored in this investigation.

The research question for this investigation was:

Do the students' IGCSE exam result scores (igcse), their English scores (eng) in IGCSE, and their IBDP mock exam scores significantly predict students' IBDP outcome scores?

\section{METHOD}

\section{Research Model}

In this quantitative study, to explore the predictors of the IB Diploma Programme outcome scores, a purposive sampling from one private IB school was selected. Multiple regression analyses were conducted to explain dependent variable: IB Diploma Programme outcome scores. Adequate sample size to conduct multiple regression analysis was achieved according to the following calculation provided by Green (1991). Green stated that as long as the $N \geq 50+8 k$ where k represents the number of independent variables, there is adequate sample size. In this study where $N=123$ participants were used there were 3 independent variables therefore the equation was calculated as follows:

$$
N \geq 50+24
$$

\section{The Study Group}

A purposive sample of 123 high school students $\left(N_{\text {female }}=59\right)$ was drawn from a private laboratory school which offers bilingual national and international curricula to the students living in Eastern Turkey. This school was established by a Turkish university, legitimized with an enacted law in parliament, in 2007 as one of the four K-12 schools in the eastern region of Turkey, an area where there is limited access to quality education. The high school, from which the sample was selected, follows a mixture of international and national curriculum. It has a preparatory year for English language learning before grade 9 . In grades 9 and 10 all students follow IGCSE and the ones who pass the exit level exam earn the right to continue the school the IB Diploma Programme in grades 11 and 12. 
Although the school offered two different curricula, junior high school (grades 9-10) and IBDP (grades 11-12), almost all students were Turkish. The school was not an international school however there were currently 7 international teachers; two of whom was teaching DP courses. There was a diverse socio-economic status from privileged to underprivileged by getting financial support from the school foundation. The greatest number of students, $85 \%$, had scholarship since they passed the entrance examination with the desired expectations to be able to start prep class. There was no student accepted to the school without taking the entrance exam or only by tuition without any passing score. Regarding what is reported by Smits and Hoşgör (2006) in a research on Turkey about the effects of family background on educational participation, parents' educational level, occupation and income had positive effects on their children's progress in school. When eastern and southeastern regions of Turkey considered by Smits and Hoşgör, they reported that most of the women had not attended or completed primary school. They also concluded some factors to be considered as the inhibitors for students' academic achievement such as low income, low maternal education, speaking language of mother other than Turkish, more than four siblings, and living in the east and in the countryside.

\section{Variables}

The dependent variable of the study was IBDP outcome scores out of 42 (IBDP Results; range 0-42), whilst IGCSE outcome scores (IGCSE Results; range A*-F, 0-42), English achievement level (range $A^{*}$-E, 1-7), and IBDP mock results (range 0-42) were the independent variables. IB outcome scores are out of 45 points in total however, for this study the IGCSE results were transformed from $A^{*}$-F level to 1-7 level and it made 42 in total since the students got 6 courses and can achieve maximum $A^{*}$ and/or 7 in each course. Therefore in IBDP mock results bonus points from Creativity Action and Service (CAS) and Extended Essay (EE) were not included to be able to get 42 as the total score. IBDP Mock exams were prepared by the school teachers including past exam paper questions gathered from IBO. There was no outlier deviated from the mean by more than three standard deviations. The normality assumption was checked and the variation inflation factor (VIF) values were consulted for a multicolliniarity threat. These were tolerable (Tabachnick \& Fidell, 2007). The variables are described below for clarity.

Diploma Programme Examination Scores (dp): Students are required to take external examinations in six different courses, which they choose according to their career planning. External examination of each course is marked out of seven points. This variable was measured at the interval level and the maximum possible number of points from six IBDP courses is 42 .

Diploma Programme Mock Examination (mock): The examination which is conducted under similar exam setting where students write their exams in exactly the same duration required by IBO. Mock exam papers are prepared by the teachers by using past DP exam questions and official mark schemes to mark the papers. 
IGCSE Score: Students are required to take external examinations in six different courses before Diploma Programme. External examination of each course is calculated out of seven points. This variable was also measured at the interval level, and the maximum possible number of points from six IGCSE courses is also 42 .

\section{Data Collection-Timeline}

The IGCSE and IBDP scores were given by the corresponding organisation and announced to the school with an official letter. All of these scores were obtained in their original format from the school. As explained in this section below, the IBDP mock results were given by the IBDP teachers of the students. Therefore these scores were obtained in an excel sheet from the school. The school year started in September and the academic year continues until the end of June. The data collection took place in 2 academic years. After the IGCSE results (igcse and english) were announced at the end of grade 10, successful students officially started their IBDP studies in grade 11. The IGCSE and English scores were obtained for 123 high school students at the end of their grade 10 when the IGCSE exam results were announced. The unsuccessful students' scores were not included in data collection process since they were not allowed to continue studying IBDP at the school. As these 123 students started their first year of IBDP, there were no data available for this study until they took their mock exams. Mock exams (mock) were administered in March-April in grade 12. Teachers hand in their predicted grades before the IBDP exam in May of grade 12. The results of the IBDP exams are announced in July at the end of grade 12. The data for all the variables were collected in the aforementioned corresponding dates.

\section{Data Analysis}

Before conducting the multiple regression analysis, linear relationship between the dependent and independent variables, multivariate normality, and multicollinearity were controlled. Scatterplots showed that there was a linear relationship between the dependent variable and independent variables. As shown in, the independent variables were not highly correlated with each other the VIF values were lower than 5.00 which shows that there is not a serious multicollinearity problem (James et al, 2009; Hair et al., 2014; Tabachnick \& Fidell, 2001). The correlation coefficients were computed to describe the bivariate relationships between the variables in Table 1.

After checking all the assumptions to conduct multiple regression analysis was conducted on SPSS for one dependent variable, the IBDP outcome scores.

The results of multiple regression analysis was given in both unstandardized (B) and standardized $(\beta)$ regression weights, in addition to visual representation. 


\section{Table 1.}

Correlation Matrix

dp igcse english mock

Variables

\begin{tabular}{lllll}
\hline $\mathrm{dp}$ & 1 & $.71^{*}$ & $.59^{*}$ & $.84^{*}$ \\
igcse & 1 & $.42^{*}$ & $.70^{*}$ \\
English & & 1 & $.51^{*}$ \\
Mock & & & 1
\end{tabular}

Note. ${ }^{*}$ Correlation is significant at the .05 level

\section{FINDINGS}

It can be deducted from Table 2 that mock results are very close to students' real dp scores. Teachers are recommended by IBO to give their predicted grades (pg) based on all the evidence of students' work including the mock results and the teacher's knowledge of IB's standards (IBO, 2015). And in this particular school teachers rely on the mock exam results which were also prepared by the teachers who used past DP exam questions and official mark schemes to mark the papers. Therefore, it is expected that the students may show a very similar performance during the real exam setting.

Table 2.

Descriptive Statistics

\begin{tabular}{llllll}
\hline & Mean & Std. Dev. & Range & Skewness & Kurtosis \\
\hline Dp & 31.11 & 3.82 & $0-42$ & .13 & .37 \\
igcse & 34.80 & 3.95 & $0-42$ & -.22 & -.84 \\
Mock & 31.23 & 4.58 & $0-42$ & .18 & -.55 \\
English & 5.73 & 0.69 & $0-7$ & -.35 & .20 \\
\hline
\end{tabular}

\section{Multiple Regression Results for IBDP}

Multiple regression analysis with enter method was conducted to evaluate the extent that IBDP outcome scores could be predicted by the IGCSE results and students' English achievement level. The other predictor in the model was IBDP mock exam results conducted at school by using the past IB exam questions. The only aim of using the enter method was to compute multiple regression equations which were specified in advance. 
All variables were already planned to be included therefore not other method was considered.

Table 3.

Unstandardized and standardized regression coefficients

\begin{tabular}{llllll}
\hline Model & Variables & $B$ & $\beta$ & $p$ & VIF \\
\hline 1 & (Constant) & 2.02 & & & \\
& Igcse & .22 & .23 & .00 & 1.95 \\
& English & 1.15 & .21 & .00 & 1.36 \\
& Mock & .48 & .57 & .00 & 2.17 \\
& & & & \\
\hline
\end{tabular}

The model was found to explain $76 \%$ of IBDP results. This finding indicated that if the students could increase their mock exam results by 1 point, their IBDP results would increase .57 points. If they could increase their English achievement level by 1 point, their IBDP results would increase .21 points additionally if their IGCSE results could increase 1 point, their IBDP results would increase .23 points.

The multiple regression model explained $76 \%$ of the total variance in IBDP results $\left(\mathrm{R}^{2}=\right.$ .76 ; $\mathrm{R}^{2}$ adjusted $=.76, \mathrm{p}<.05$ )

The regression equation with three predictors was given as follows in the model,

IB_results $=2.02+.22($ IGCSE results $)+1.15($ English achievement $)+.48($ IBDP Mock results)

A path diagram was also drawn to visually represent the model. The numbers by the arrows toward IBDP results variable indicated the standardized regression weights (figure 1), whereas numbers by the arrows between predictors were the bivariate correlation coefficients. 


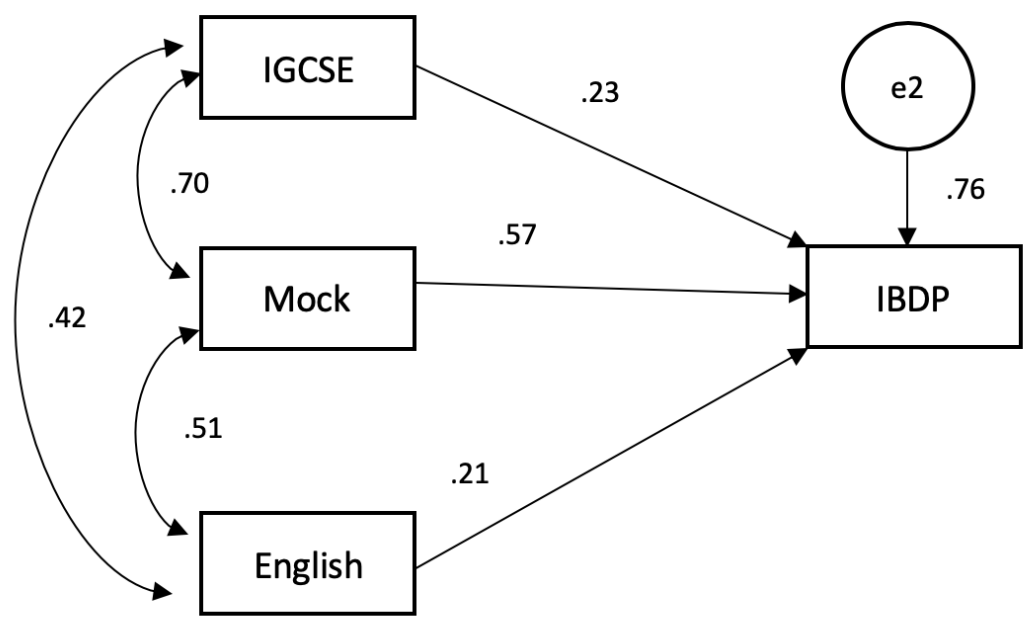

Figure 1. Visual Representation of Regression Model that Predicts IBDP Scores

\section{RESULTS, DISCUSSIONS AND SUGGESTIONS}

The aim of this study was to explore the predictors of IBDP outcome scores by using the IGCSE exam results, English achievement level, and IBDP mock exam results. Multiple regression analysis was conducted for one dependent variable on SPSS to find a model which can explain the predictors of the IBDP outcome scores. The model was found to explain $76 \%$ of the IBDP outcome scores. In this model IGCSE exam results seem to be important indicator for both students and the teachers. As supported by Monteath (2015), regional director of Cambridge Assessment International Education (CAIE), in recent years the IGCSE has been considered as pre-IBDP programme along with its many other goals. One of the reasons that schools consider this programme as an advantageous preparation stage for the students who will continue with IBDP is its similar external exams. Students are taking the exam in English language and they are writing these papers in an exam setting where the exam papers are organised by the international examination board. As also reported in the research done by ACER (2015), IGCSE students shared that the programme is helping them develop writing skills which in turn helps their success in IBDP. The findings in the regression model in this study seem to be parallel with these benefits of IGCSE reported in the literature. The IGCSE is perceived by students to prepare them for the IBDP, develop their learning strategies (metacognitive skills and selfregulated learning) and dispositions (attitudes and motivation towards learning) in support of their critical thinking skills. However, all of the students participated in a study agreed that the most useful part of the IGCSE is its similar exam structure with the IBDP (Dulun, 2018).

However, in the regression model which explains the $76 \%$ of the IBDP exam score variance, the mock examinations seem to be as important as the IGCSE achievement level. 
The importance of IBDP mock exam results to predict the IBDP outcome scores is because of the exam questions and answer keys used by the teachers in these exams. In mock exams, teachers aim to evaluate the readiness of the students by using the IBDP exam questions from the previous years' examination papers. Although the teachers are not usually the expert examiners of these exams, they use the official exam mark schemes prepared by the official exam developers from the IB. Therefore, the role of mock exam scores as a predictor can easily be understood here in the regression model. This shows that the teachers must give at least one mock exam for the students to evaluate their academic readiness for the IBDP exams through the end of $2^{\text {nd }}$ year before the real IBDP examinations take place.

Although the IBDP mock exam results were found to have a predicting role on the IBDP outcome scores the English levels of the students should also be considered by IBDP teachers to predict the students' IBDP outcome scores. Language of instruction in both IGCSE and IBDP is English which is another challenge for Turkish students in this study because all were second language learners. Subject area teachers may not be aware of the students' performance in second language course and not even be aware of his/her writing skills in second language to express his/her thoughts although this may be evident in some cases when the mock examinations are provided. For instance, in Biology lesson there are extended response questions in examination papers which require the students to express their knowledge clearly and in an organized way. If the student cannot express his /her knowledge in second language then his paper may not be at satisfactory standard although the teacher and the student agree that his/her knowledge and skills are satisfactory to pass Biology exam. Based on experience with this particular study group in this particular school, this kind of situation happened when students were English B students and they were taking high level science courses in IBDP. According to the school records, they all passed English B with the average score of 6 out of 7 however $25 \%$ of them failed science courses delivered in English language which was their second language. The teachers should not forget that the students must be able to express their thoughts and knowledge in the language that they will write their official exam papers. The students as in this case may not have the luxury to study in their mother tongue in preparation to their IBDP examinations therefore the teachers should ensure that the courses are delivered in official exam language even it is sometimes hard for students and they may need to hear the explanation in their own language to understand in order to help students prepare better for their DP examinations.

There is an increase in number of evidences that language proficiency has significant impacts on students' academic performances in science and mathematics as cited by Ercikan et. al (2015) (Abedi \& Lord, 2001; Abedi, 2004; Abedi, Hofstetter, \& Lord, 2004; Butler et al., 2004; Kopriva, Gabel, \& Cameron, 2011; Luykx et al., 2007; Penfield \& Lee, 2010; Solano-Flores \& Trumbull, 2003).

Maths and science teachers have concerns that the students have to learn key terminology in English since marks are only available to key terms in the exam mark schemes as it is also the case in Tan \& Lan's research (2010). 
The use of teachers' English in a classroom changes according to the linguistic capacity of students which leads a bilingual classroom instead of an English-medium classroom (Tan \& Lan, 2010). This is also observed in this particular case where this research was conducted. Teachers are observed to be in a very similar situation to Tan \& Lan's study in a Malaysian context that they reduce and simplify the content and language to teach the poor students only the topics from the syllabus which must be known to pass the exam. The findings are also supporting Lemke (1990) who said that successful learning of science and mathematics requires mastering the language. When the students in this context are considered as ELL who have no access other than the school to science and mathematics in English, it is much harder for them to master their second language. And the solution teachers come up with is to simplify the language and focus on key terms for students to comprehend the content (Tan \& Lan, 2010).

The language of the examination may also limit students' access to their knowledge and ability to respond to the questions when they have limited language proficiency (Ercikan et al., 2015).

A recommendation to the teachers as Moschkovich (n.d) suggested could be to address focus on engaging the students more in discussions as they learn English. This contradicts with what many teachers do while trying to simplify the content and language for ELLs. All students regardless of their level of English, must be encouraged to participate in discussions where they can use mathematical ideas, concepts and reasoning. Teachers must not focus on their pronunciation, vocabulary or their linguistic skills but they should focus on the way how they express their mathematical knowledge and how they use their mathematical reasoning (Moschkovich, nd).

The coordinators, counselors and the teachers may use the models presented in this study to support the students' choices in IBDP for a better academic success by evaluating the students' performances in second language (English) and IGCSE.

The model which was found to explain $76 \%$ of the IBDP results, explained in this paper can be extremely useful to the school, coordinator and the candidate to see whether a passing outcome score is highly possible to maintain the candidate's study habits during the preparation.

It is also recommended that English levels of the students should be considered when assessing student performance in IBDP; particularly, when the language of instruction is different from the native language of the students.

\section{References}

Abedi, J., \& Lord, C. (2001). The language factor in mathematics tests. Applied Measurement in Education, 14(3), 219-234.

Abedi, J. (2004). The No Child Left Behind Act and English language learners: Assessment and accountability issues. Educational Researcher, 33(1), 4-14. 
Abedi, J., Hofstetter, C., \& Lord, C. (2004). Assessment accommodations for English language learners: Implications for policy-based empirical research. Review of Educational Research, 74(1), 1-28.

ACER, Australian Council for Educational Research. 2015. The International Baccalaureate (IB) Middle Years Programme (MYP): Comparing IB Diploma Programme outcomes of students who complete the MYP and other middle years courses of study. Retrieved from International Baccalaureate Organisation website: https://www.ibo.org/globalassets/publications/ibresearch/myp/comparing-dp-outcomes-with-myp-report-en.pdf

Butler, F. A., Bailey, A. L., Stevens, R., Huang, B., \& Lord, C. (2004). Academic English in Fifth-Grade Mathematics, Science and Social Studies Textbooks (CSE Tech. Rep. No. 642). Los Angeles: University of California, National Center for Research on Evaluation, Standards, and Student Testing (CRESST).

CAIE, Cambridge Assessment Internation Education. (2018a). Our history. Retrieved from http://www.cambridgeinternational.org/about-us/who-we-are/our-history/

CAIE, Cambridge Assessment International Education. (2018b). Cambridge IGCSE curriculum. Retrieved from

http://www.cambridgeinternational.org/programmes-and-qualifications/cambridge-secondary2/cambridge-igcse/curriculum/

Corlu, M. S. (2014). Which preparatory curriculum for the International Baccalaureate Diploma Program is best? The challenge for international schools with regard to mathematics and science. International Review of Education, 60(6), 793-801. http://dx.doi.org/10.1007/s11159014-9446-9

Dulun, Ö., Lane, J. F., \& Ateşkan, A. (2018). Student perceptions of successful learning support for an international high school programme: a comparative case study in Turkey. Compare: $A$ Journal of Comparative and International Education.

Dulun, Ö. (2018). Student perceptions of successful preparation for IBDP: implications for developing 21st century skills. Doctoral dissertation. Bilkent University, Ankara, Turkey.

Ercikan, K., Chen, M. Y., Thomas, J., Goodrich, S., Sandilands, D., Roth W., \& Simon, M. (2015). Reading proficiency and comparability of mathematics and science scores for students from English and non-English backgrounds: an international perspective. International Journal of Testing, 15, 153-175.

Green, S. B. (1991). How Many Subjects Does It Take To Do A Regression Analysis. Multivariate Behavioral Research, 26(3), 499-510. doi: 10.1207/s15327906mbr2603_7

Hair, J. F. Jr., Black, W. C., Babin, B. J., \& Anderson, R. E. (2014). Multivariate Data Analysis, Seventh edition. Pearson.

IBO, International Baccalaureate Organization (2015). Handbook of procedures for the diploma programme. Retrieved from

https://ibpublishing.ibo.org/server3/apps/handbook/index.html?doc=d 0 dpyyy vmx 14091 e\&part $=11 \&$ chapter $=6$

IBO, International Baccalaureate Organisation. (2017). What is an IB education? Retrieved from http://www.ibo.org/globalassets/what-is-an-ib-education- 2017-en.pdf

IBO, International Baccalaureate Organisation. (2018). What is the DP? Retrieved from https://www.ibo.org/programmes/diploma-programme/ 
IBO, International Baccalaureate Organisation. (2019). Facts and Figures. Retrieved from http://www.ibo.org/about-the-ib/facts-and-figures/

James, G., Witten, D., Hastie, T., \& Tibshirani, R. (2017). An Introduction to Statistical Learning: with Applications in R. New York: Springer.

Kamalaldin, A., Michel, C., \& Sweet, K. (2016). Cultivating the future: Sustainability education and the international baccalaureate programme. Blekinge Institute of Technology, Sweden.

Kaplan, A. (1998). Clarifying metacognition, self-regulation, and self-regulated learning: what's the purpose? Educational Psychology Review, 27, 447-484.

Kopriva, R. J., Gabel, D., \& Cameron, C. (2011). Designing dynamic and interactive assessments for English learners which directly measure targeted science constructs. Paper presented at the American Education Research Association Annual Meeting, New Orleans, LA, USA.

Lemke, J. L. (1990). Talking science: Language, learning and values. Stanford: Ablesc/JAI Publishing Corporation.

MEB. (2014). Milli eğitim bakanlı̆̆ı ortaöğretim kurumları yönetmeliği. Retrieved from http://mevzuat.meb.gov.tr/html/ortaogrkurumyon 0/ortaogrkurumyon 1.html

Monteath, P. (2015, Spring). Cambridge International Examinations, going global. Conference Common $\quad$ Room, $2(1)$ Retrieved from http://www.johncatt.com/downloads/ccr52_1/offline/download.pdf

Moschkovich, J. (n.d). Mathematics, the common core, and language: recommendations for mathematics instruction for ELs aligned with the common core. Understanding Language: Language, Literacy, and Learning in the Content Areas. Retrieved from http://ell.stanford.edu/sites/default/files/pdf/academic-papers/02IMoschkovich\%20Math\%20FINAL bound\%20with\%20appendix.pdf

Penfield, R. D., \& Lee, O. (2010). Test-based accountability: Potential benefits and pitfalls of science assessment with student diversity. Journal of Research in Science Traching, 47(1), 6-24.

Sagun, S., \& Corlu, M. S. (2014). Resolving the dilemma of international school curriculum: The case of biology. Eurasia Journal of Mathematics, Science, and Technology Education, 10(2), 153-158

Smits, J., Gündüz-Hosgör, A. (2006). Effects of family background characteristics on educational participation in Turkey. International Journal of Educational Development, 26, 545-560.

Solano-Flores, G., \& Trumbull, E. (2003). Examining language in context: The need for new research and practice paradigms in the testing of English-language learners. Educational Researcher, 32(2), 3-13.

Suldo, S. M., Shaunessy, E., \& Hardesty, R. (2008). Relationship among stress, coping, and mental health in high-achieving high school students. Psychology in the Schools, 45(4), 273-290.

Tabachnick, B. G., \& Fidell, L. S. (2001). Using Multivariate Statistics, Fourth Edition. Needham Heights, MA: Allyn \& Bacon.

Tan, M., \& Lan, O. S., (2010). Teaching mathematics and science in English in Malaysian classrooms: the impact of teacher beliefs on classroom practices and student learning. Journal of English for Academic Purposes, 10(2011), 5-18.

Thompson, J. J. (1998). Towards a model for international education. International Education: Principles and Practice, 276-290.

Thompson, B. (2008). Foundations of behavioral statistics: An insight-based approach. New York: Guilford. 
Trilling, B., \& Fadel, C. (2009). 21st Century Skills: Learning for Life in our Times. San Francisco, California, USA. John Wiley \& Sons, Inc.

Zimmerman, B. J., \& Schunk, D. (1989). Self-regulated learning and academic achievement. New York, USA. Springer-Verlag.

\section{Acknowledgements}

I would like to thank Assoc. Prof. Dr. M. Sencer Corlu, director of BAUSTEM Center at Bahçeșehir University for his expert advise in useful discussions and support. 
In the writing process of the study titled "Investigating the Predictors of the Diploma Programme Outcome Scores", the rules of scientific, ethical and citation were followed; it was undertaken by the authors of this study that no falsification was made on the collected data. "Sakarya University Journal of Education Journal and Editor" had no responsibility for all ethical violations to be encountered, and all responsibility belongs to the authors and that the study was not submitted for evaluation to any other academic publishing environment. 